See Article page 1007.

\section{Commentary: Once again- the heart and the brain}

\author{
Justus Reitz ${ }^{\mathrm{a}}$ and Can Yerebakan, MD
}

Nowadays the vast majority of children born with congenital heart disease (CHD) will reach adulthood, ${ }^{1}$ but children with CHD are still at increased risk of developmental disorders, disabilities, or development delay. ${ }^{2}$ Although life expectancy is steadily rising even in cases of complex CHD, efforts to ensure a good long-term neurologic outcome of patients with CHD are warranted. Because it has been shown that brain injury may already be present in patients with $\mathrm{CHD}$ preoperatively, and that prenatal brain immaturity increases the risk of postoperative brain injury, ${ }^{3}$ it is highly relevant to investigate the connection and potential prenatal risk factors of brain immaturity and injury in this group.

In this issue of the Journal, Peyvandi and colleagues ${ }^{4}$ report their longitudinal multicenter study demonstrating the association between lower total brain volume (TBV) and elevated risk of acquired neonatal preoperative white matter injury (WMI) in patients with dextro-transposition of the great arteries (d-TGA). For this purpose, the cohort comprised 63 patients, including 37 with d-TGA and 26 with hypoplastic left heart syndrome (HLHS) with fetal (third trimester) as well as postnatal preoperative brain magnetic resonance imaging (MRI). TBV and WMI were scored on prenatal and neonatal MRI. Repeated-measures analysis for the d-TGA group, adjusted for both postmenstrual age at MRI and site, revealed that overall TBV was lower in patients with acquired moderate to severe WMI each week from fetal to neonatal life compared with those with none/mild WMI. The increase in TBV did not differ by injury group. Interestingly, in patients with HLHS, no association was found between TBV and increases in TBV or postnatal brain injury.

From the ${ }^{\mathrm{a}}$ Division of Prenatal Medicine and Fetal Therapy, Justus-Liebig-University, Giessen, Germany; and 'Department of Cardiovascular Surgery, Children's National Heart Institute, Children's National Hospital, The George Washington University School of Medicine and Health Sciences, Washington, DC.

Disclosures: The authors reported no conflicts of interest.

The Journal policy requires editors and reviewers to disclose conflicts of interest and to decline handling or reviewing manuscripts for which they may have a conflict of interest. The editors and reviewers of this article have no conflicts of interest.

Received for publication Nov 17, 2020; revisions received Nov 17, 2020; accepted for publication Nov 18, 2020; available ahead of print Nov 30, 2020.

Address for reprints: Can Yerebakan, MD, Cardiovascular Surgery, Children's National Heart Institute, Children's National Hospital, The George Washington University School of Medicine and Health Sciences, 111 Michigan Ave NW, Washington, DC 20010 (E-mail: cyerebakan@childrensnational.org).

J Thorac Cardiovasc Surg 2021;162:1017-8 0022-5223/ $\$ 36.00$

Copyright (c) 2020 Published by Elsevier Inc. on behalf of The American Association for Thoracic Surgery

https://doi.org/10.1016/j.jtcvs.2020.11.079

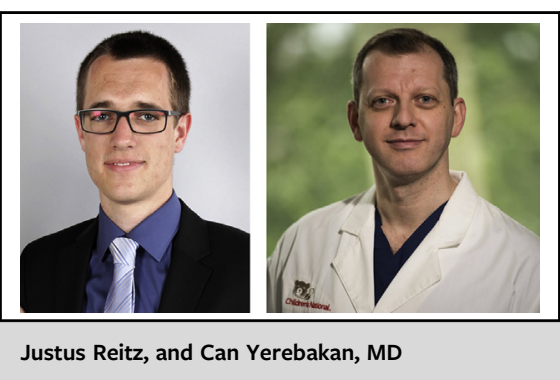

CENTRAL MESSAGE

Low total brain volume is a predictor for preoperative white matter injury in dextrotransposition of the great arteries but not in hypoplastic left heart syndrome.

The authors point out the pathophysiological background of these findings and possible underlying causes of prenatal and postnatal brain injury in patients with CHD. Starting at midgestation, oligodendrocytes originate from the subventricular zone, migrate, expand, and speed myelination, resulting in new connections of neurons. ${ }^{5}$ In this period, the fetal brain develops from a smooth mass toward its fully grown form with gyri and sulci. This differentiated process is highly susceptible to negative influences, such as malnutrition and hypoxemia, often prevalent in fetuses with CHD. As a result, it could be shown that in fetuses with CHD, cortical gyrification is reduced, and $25 \%$ of children with complex CHD are microcephalic at birth. ${ }^{6,7}$ This has been strongly associated with brain injuries ${ }^{8}$ and neurodevelopmental abnormalities, and the authors' findings strengthen this hypothesis.

Nonetheless, these findings do not explain why lower TBV is predictive for higher postnatal WMI in the d-TGA group but not in the HLHS group. The authors speculate that even though nutrient and oxygen delivery to the brain is believed to be similar in HLHS and d-TGA, the physiology during the transition from fetal to neonatal circulation could have a major impact on the brain and result in an increased risk for cerebral hypoxia in the perinatal period. This thesis is supported by an increasing number of studies pointing out that earlier repair of d-TGA is associated with better brain health. Lim and colleagues ${ }^{9}$ recently contributed to this topic by showing that surgery in patients with d-TGA beyond age 2 weeks is associated with impaired brain growth and slower language development. This highlights once more that among the many preoperative risk factors for brain injury, establishing normal oxygen and 
nutrient delivery to the rapidly developing neonatal brain earlier, by preponed surgery in d-TGA, might be an effective strategy to reduce brain injury. Considering the findings of Peyvandi and colleagues, patients with d-TGA and low TBV could especially benefit from this strategy. Further studies are needed to investigate the origin and predictors of preoperative brain injuries and strategies to prevent them.

These findings add an important piece to the puzzle of myriad risk factors for neurodevelopmental delays in children with CHD. ${ }^{10-12}$ As a result, TBV analysis in prenatal brain MRI can be used for a fetus with d-TGA as a predictor for increased risk of postnatal brain injury, and accordingly, adapted perinatal management in this highrisk group can be planned in advance. We congratulate Peyvandi and colleagues for their excellent work.

\section{References}

1. Marelli AJ, Ionescu-Ittu R, Mackie AS, Guo L, Dendukuri N, Kaouache M. Lifetime prevalence of congenital heart disease in the general population from 2000 to 2010. Circulation. 2014;130:749-56.

2. Mussatto KA, Hoffmann RG, Hoffman GM, Tweddell JS, Bear L, Cao Y, et al. Risk and prevalence of developmental delay in young children with congenital heart disease. Pediatrics. 2014;133:e570-7.

3. Limperopoulos C, Majnemer A, Shevell MI, Rosenblatt B, Rohlicek C, Tchervenkov C. Neurodevelopmental status of newborns and infants with congenital heart defects before and after open heart surgery. J Pediatr. 2000; 137:638-45.

4. Peyvandi S, Lim JM, Marini D, Xu D, Reddy VM, Barkovich AJ, et al. Fetal brain growth and risk of postnatal white matter injury in critical congenital heart disease. J Thorac Cardiovasc Surg. 2021;162:1007-14.e1.

5. Morton PD, Ishibashi N, Jonas RA. Neurodevelopmental abnormalities and congenital heart disease: insights into altered brain maturation. Circ Res. 2017; 120:960-77.

6. Clouchoux C, du Plessis AJ, Bouyssi-Kobar M, Tworetzky W, McElhinney DB, Brown DW, et al. Delayed cortical development in fetuses with complex congenital heart disease. Cereb Cortex. 2013;23:2932-43.

7. Miller SP, McQuillen PS, Hamrick S, Xu D, Glidden DV, Charlton N, et al. Abnormal brain development in newborns with congenital heart disease. $N$ Engl J Med. 2007;357:1928-38.

8. Hinton RB, Andelfinger G, Sekar P, Hinton AC, Gendron RL, Michelfelder EC, et al. Prenatal head growth and white matter injury in hypoplastic left heart syndrome. Pediatr Res. 2008;64:364-9.

9. Lim JM, Porayette P, Marini D, Chau V, Au-Young SH, Saini A, et al. Associations between age at arterial switch operation, brain growth, and development in infants with transposition of the great arteries. Circulation. 2019;139:2728-38.

10. Petit CJ, Rome JJ, Wernovsky G, Mason SE, Shera DM, Nicolson SC, et al. Preoperative brain injury in transposition of the great arteries is associated with oxygenation and time to surgery, not balloon atrial septostomy. Circulation. 2009;119:709-16.

11. Dimitropoulos A, McQuillen PS, Sethi V, Moosa A, Chau V, Xu D, et al. Brain injury and development in newborns with critical congenital heart disease. Neurology. 2013;81:241-8.

12. Goff DA, Shera DM, Tang S, Lavin NA, Durning SM, Nicolson SC, et al. Risk factors for preoperative periventricular leukomalacia in term neonates with hypoplastic left heart syndrome are patient related. J Thorac Cardiovasc Surg. 2014;147:1312-8.

\section{Commentary: Will fetal brain magnetic resonance imaging guide our timing of surgery for hypoplastic left heart syndrome and transposition of the great arteries?}

\author{
Syed Murfad Peer, MD, and \\ Yves d'Udekem, MD, PhD
}

\footnotetext{
Department of Cardiovascular Surgery, Children's National Heart Institute, The George Washington University School of Medicine, Washington, DC

Disclosures: The authors reported no conflicts of interest.

The Journal policy requires editors and reviewers to disclose conflicts of interest and to decline handling or reviewing manuscripts for which they may have a conflict of interest. The editors and reviewers of this article have no conflicts of interest.

Received for publication Oct 27, 2020; revisions received Oct 27, 2020; accepted for publication Oct 27, 2020; available ahead of print Nov 5, 2020.

Address for reprints: Yves d'Udekem, MD, PhD, Department of Cardiovascular Surgery, Children's National Heart Institute, The George Washington University School of Medicine, 111 Michigan Ave NW, Washington, DC 20010 (E-mail: yves.dudekem@childrensnational.org).

J Thorac Cardiovasc Surg 2021;162:1018-9

$0022-5223 / \$ 36.00$

Copyright (c) 2020 by The American Association for Thoracic Surgery

https://doi.org/10.1016/j.jtcvs.2020.10.109
}

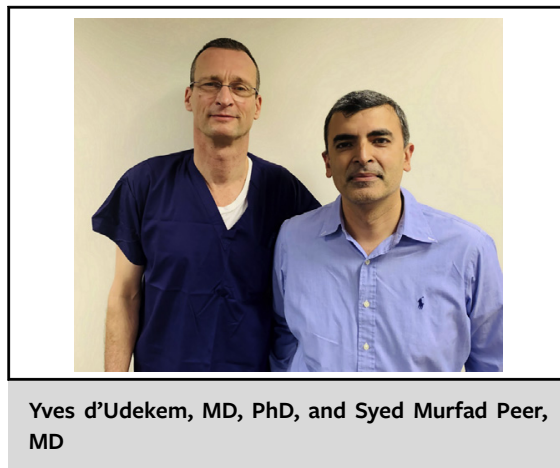

CENTRAL MESSAGE

Elucidating the mechanism of white matter injury in critical congenital heart disease could help us predict neurodevelopmental outcomes.

With the decreasing mortality after congenital heart surgery, neurodevelopmental outcomes have become an area 